\title{
Das Políticas do Prazer: o lazer no pensamento biblioteconômico-informacional e sua dimensão aplicada na institucionalidade das bibliotecas
}

\author{
About pleasure policies: leisure in Library and Information Science thinking terms and its \\ dimension applied to library institutionalization
}

\begin{abstract}
Gustavo Silva Saldanha
Doutor em Ciência da Informação pelo Instituto Brasileiro de Informação em Ciência e Tecnologia FACC/UFRJ.

Professor Assistente da Escola de Biblioteconomia da Universidade Federal do Estado do Rio de Janeiro -

UNIRIO.

E-mail: saldanhaquim@gmail.com

Rachel de Melo Vellozo Pereira

Bacharel em Biblioteconomia pela Universidade Federal do Estado do Rio de Janeiro

E-mail: rachelprr@yahoo.com.br
\end{abstract}

\begin{abstract}
Resumo
A biblioteca como um espaço de lazer foi o objeto aplicado do presente estudo. No plano macro problematizou-se a questão da construção de mecanismos de desenvolvimento de políticas de entretenimento em Biblioteconomia e Ciência da Informação. O objetivo geral foi analisar o lazer, no pensamento biblioteconômico-informacional, a partir de suas abordagens teóricas e sua materialidade institucional, centralizando aqui a biblioteca e sua fisicalidade. Os procedimentos metodológicos foram realizados através do estudo bibliográfico na literatura especializada. A partir do aporte bibliográfico, analisou-se os conceitos de ação cultural, animação cultural e lazer. Analisou-se também o conjunto de abordagens sobre o lazer em bibliotecas, abordagens tais que dizem respeito à aproximação ao conceito de lazer na literatura especializada em Biblioteconomia e Ciência da Informação. São elas: abordagem sobre ação cultural e animação cultural, que visam proporcionar um espaço de lazer na biblioteca; e a abordagem sobre a biblioteca como (diretamente) espaço de lazer. Observou-se que as correntes referentes ao lazer, ação cultural e animação cultural, merecem maior atenção, dada a escassez de reflexão crítica na literatura especializada. Observou-se, por fim, em tais abordagens, a existência de gestos políticos que podem contribuir para o lazer, em diálogo com a institucionalidade da biblioteca estabelecida a partir de sua materialidade (seu espaço físico). Porém, estes ainda permanecem distantes da gestualidade das escolhas intersubjetivas.
\end{abstract}

Palavras-chave: Biblioteconomia e Ciência da Informação. Biblioteca. Lazer. Ação Cultural. Animação Cultural.

\begin{abstract}
The library viewed as a leisure space was the object of study of the present article. The issue of the construction of mechanisms to develop policies of entertainment in the scope of Library and Information Science is discussed. The general objective was to analyze leisure, in Library Science and Information Science thinking terms, starting from its theoretical approaches and its institutional concreteness. Methodological procedures were carried out through bibliographical study in specialized literature. An analysis of the concepts of cultural action, cultural animation, and leisure began with the bibliographical input; and the library, in general, concerning the usefulness of its physical space. Likewise, an analysis of the set of approaches about leisure in libraries, concerning their closeness to the concept of leisure in Library and Information Science. They are: the approach on cultural action and cultural activities providing leisure space at the library; and the approach on the library as leisure space. It was observed that the studies referring to leisure, cultural action, and cultural activities deserve greater attention, given its scarcity in literature. It is worth pointing out the limitations of the present article and indications to new research, in order to critically enrich the studies dedicated to the leisure domain in libraries and in Library and Information Science literature.
\end{abstract}

Keywords: Library and Information Science. Library. Leisure. Cultural Action. Cultural Activities.

InCID: R. Ci. Inf. e Doc., Ribeirão Preto, v. 7, n. 1, p. 05-28, mar./ago. 2016.

DOI: 10.11606/issn.2178-2075.v7i1p5-28 
Das Políticas do Prazer: o lazer no pensamento biblioteconômico-informacional e sua dimensão aplicada na institucionalidade das bibliotecas

\section{Introdução ao Lazer: notas iniciais sobre a informação e o deleite}

Pense numa biblioteca aberta em período integral, onde a comunidade pudesse aproveitar a hora do almoço para desfrutar de uma boa leitura. Pense numa biblioteca aberta no período de férias escolares, nos fins de semana, para que fosse aproveitada como mais uma forma de lazer. Por enquanto, talvez seja somente um sonho. (PIMENTEL, 2007, p. 32).

Em Promoting Intellectual Freedom Globally through Libraries: the Role of IFLA, discutindo o desenvolvimento da liberdade intelectual a partir da Declaração Universal dos Direitos Humanos e do Manifesto das Bibliotecas Públicas da Unesco, em diálogo com as ações da International Federation of Library Association and Institutions (IFLA), Alex Byrne (2000) chamava a atenção para a relevância da atuação de bibliotecários na institucionalização de práticas de promoção do livre pensar. Em sua visão, a relação entre liberdade intelectual e as bibliotecas não passa apenas pela disponibilização de documentos técnico-científicos, mas também por recursos que educam e divertem crianças - e, por extensão, todo e qualquer cidadão. Byrne (2000) destacava, em seu debate, a criação, a partir de 1997, de um fórum específico dentro da IFLA para desenvolver tal discussão, o Committee on Free Access to Information and Freedom of Expression (FAIFE).

Um primeiro questionamento que nos cerca, fonte inicial das inquietações deste estudo, é: em que medida as políticas para liberdade intelectual e a liberdade de expressão contemplam a formação de uma perspectiva cultural crítica, a partir das relações entre sociedade e entretenimento? A única saída para uma crítica cultural da sociedade da informação seria tomála como uma sociedade do espetáculo, à moda debordiana? Em outras palavras, afora a crítica ao imperialismo informacional, a saída cultural para o acesso ao "livro do mundo" e ao "livro da sociedade" nos "jogaria" sempre para a compreensão das manobras de mídias de massa inseridas dentro da web, gerando as antigas e as promissoras formas de alienação pela passividade do lazer, tendo a Escola de Frankfurt como única solução epistemológica plausível?

No contexto de desenvolvimento do pensamento biblioteconômico-informacional, noções como "política de informação", "regime de informação", "governança informacional" e "infra-estrutura de informação" (GONZÁLEZ DE GÓMEZ, 2002) demarcam a pregnância da preocupação com os arranjos e os fluxos do conceito de informação e de sua aplicação no terreno do discurso sobre a política. Estas noções “políticas” evidenciam também uma dicotomia (por vezes apenas aparente, porém sempre presente) entre a indústria cultural e a indústria informacional.

InCID: R. Ci. Inf. e Doc., Ribeirão Preto, v. 7, n. 1, p. 05-28, mar./ago. 2016. 
Diferentemente da indústria cultural, que implicava, desde seu início, uma expectativa de homogeneização de seu público, no pólo da recepção, a indústria da informação, desde sua gênese, incluía uma vontade de integração econômica, no pólo da produção. (GONZÁLEZ DE GÓMEZ, 2002, p. 31).

A distinção destas indústrias e das políticas que olham ou atuam sob e sobre elas representa outro elemento contextualizador deste estudo. À procura de alguns indícios primários da preocupação com o âmbito de uma pregnância da cultura, mas no escopo do uso enquanto divertimento, fruição, liberdade dos sentidos, e de abordagens (críticas ou não, por hora) sobre políticas orientadas para este domínio, este trabalho analisou, na literatura biblioteconômico-informacional, a construção das correntes de pensamento sobre o lazer orientado para e proporcionado por bibliotecas. Observou-se a existência de gestos políticos que podem contribuir para o lazer, oriundos de abordagens como a ação cultural e a animação cultural, em diálogo com a institucionalidade da biblioteca estabelecida a partir de sua materialidade (seu espaço físico). Porém, estes ainda permanecem distantes da gestualidade das escolhas intersubjetivas. A pesquisa, neste contexto, pretendeu iluminar as possibilidades conceituais da noção de "lazer" e suas margens de aplicação, caracterizando os limites de sua definição e seus modos de aproximação dentro da Biblioteconomia e Ciência da Informação (BCI).

Partindo do pressuposto que a biblioteca "[...] representa apenas uma das formas que têm a função de favorecer a comunicação entre homens", sendo "necessário perguntar se ela representa a forma mais idônea [...]" (SERRAI, 1975, p. 160), frisa-se que "favorecer a comunicação", no âmbito não apenas informacional, mas também no cerne das sensibilidades, é essencial para estimular o diálogo e a interação entre pessoas. Reconhecendo, pois, que, historicamente, a biblioteca não se apresenta como o único espaço para "favorecer a comunicação entre homens", esta não deve, somente, "concorrer" com as outras formas de comunicação, mas também utilizá-las “a seu favor”, principalmente quando a questão é o lazer, dado que atualmente encontramos diversas formas de fruição, como por exemplo: televisão, computadores em rede (todo o manancial interativo da web), videogames, shoppings, parques etc.

A pesquisa, em sua totalidade, desenvolveu-se nas seguintes direções: a) discussão conceitual acerca das noções de "ação cultural", "animação cultural" e "lazer" (aqui estabeleceu-se a análise conceitual das definições da literatura biblioteconômicoinformacional; neste escopo, investigou-se também as fronteiras entre os discursos bibliográficos e alguns elementos constitucionais); b) discussão sobre a relação entre a prática 
Das Políticas do Prazer: o lazer no pensamento biblioteconômico-informacional e sua dimensão aplicada na institucionalidade das bibliotecas

biblioteconômica, tecida pelo bibliotecário, e os conceitos de "biblioteca" e "lazer" (neste âmbito, avaliou-se o ponto de vista panorâmico da biblioteca e o "lazer"; foram analisadas as relações entre o bibliotecário e o lazer, quanto a sua formação acadêmica e atuação profissional; e entre a biblioteca e o lazer, no caso de bibliotecas públicas e escolares); c) discussão sobre a simbolização e a materialização do espaço da biblioteca como possível ambiente para constituição de um "locus de prazer", a partir da visão de autores que destacam o uso da biblioteca.

No sentido amplo, o objetivo geral do trabalho foi analisar o lazer no contexto das bibliotecas a partir do pensamento biblioteconômico informacional expresso em sua produção bibliográfica periódica científica. Como objetivos específicos, propôs-se, para cumprir as demandas acima destacadas, a) analisar as relações entre: ação cultural, animação cultural e lazer; b) indicar abordagens sobre as possíveis possibilidades de lazer em bibliotecas.

As motivações do estudo se sustentam em assertivas tanto históricas quanto contemporâneas do campo disciplinar em evidência. Partindo do pressuposto que a ideia de que “"Informação é poder' foi um lema muito difundido nos tempos em que se tornou claro que o conhecimento acumulado não é, apenas, uma possibilidade de prazer, mas uma "condição básica de sobrevivência" (MILANESI, 2002, p. 54), procura-se aqui estabelecer uma relação objetiva junto da possibilidade de revisão comparada do "prazer do lazer" vinculado ao "poder informacional”. A citação de Luís Milanesi inspira a seguinte indagação, sustentada como questão de pesquisa preliminar: atualmente, ao preservar, organizar e disseminar informações, as bibliotecas estão apenas voltadas para a "condição básica de sobrevivência", deixando de fora a "possibilidade de prazer" que possam estas proporcionar?

Em nossa hipótese mais rasteira, cabe ao pensamento biblioteconômico-informacional avaliar esta questão. Será que as preocupações em suprir as necessidades educativas e profissionais sufocam e impedem a manifestação das necessidades referentes ao lazer? Em uma sociedade em que a informação é tratada como um produto que interfere no capital familiar, que afeta sua qualidade de vida, pode-se afirmar que esse risco é possível? Em que medida a construção de um conjunto de coletivos de indivíduos críticos também não passa pelos questionamentos dos modos de sensibilização para as diferentes formas de arte, de cultura, de gestos intersubjetivos do entretenimento?

Sabe-se que o lazer pode vir a ser "conquistado/desfrutado" também através de atividades educativas, como uma aula, uma palestra ou um curso ministrado na biblioteca, desde InCID: R. Ci. Inf. e Doc., Ribeirão Preto, v. 7, n. 1, p. 05-28, mar./ago. 2016. 
que isso cause prazer em seu público. É certo que estes caminhos podem ser mais desafiadores do que simplesmente disponibilizar uma sessão de filmes, livros de literatura ou videogames na biblioteca. As incertezas advindas das simples menções nos levam à dificuldade de reconhecimento do que pode, de fato, ser considerado como abordagem do domínio do lazer no pensamento biblioteconômico-informacional.

Ressalta-se que a biblioteca como espaço de lazer representa uma linha de pesquisa ainda pouco desenvolvida pela nossa literatura especializada. Sendo assim, espera-se com o estudo contribuir e estimular discussões mais amplas sobre o assunto e vir a estimular ainda uma abordagem política voltada para o lazer. Sendo o lazer considerado constitucionalmente um direito social conforme o Artigo $6^{\circ}$ da Constituição Federal de 1988, com redação dada pela emenda constitucional $n^{\circ} 64$, de 4 de fevereiro de $2010^{1}$, a reflexão se coloca, para além de um escopo epistemológico pré-definido, para além de uma visão fundada e encerrada em uma dada institucionalidade, no âmbito de um amplo e crítico debate sobre a sociedade (predicada ou não de "informacional").

Destaca-se ainda que, para esta etapa de apresentação dos resultados da pesquisa, considerado o espaço-tempo de discussão, optou-se pelo foco na relação entre a literatura especializada, as abordagens teóricas e suas relações entre a institucionalidade (da biblioteca) e sua espacialidade como pressupostos para o fomento do lazer, elementos estes esclarecidos em nossos "percursos metodológicos".

\footnotetext{
${ }^{1}$ Disponível em <http://www.planalto.gov.br/ccivil_ 03/constituicao/Emendas/Emc/emc64.htm\#art1 >. Acesso em: 29 abr. 2014.

InCID: R. Ci. Inf. e Doc., Ribeirão Preto, v. 7, n. 1, p. 05-28, mar./ago. 2016.
} 
Das Políticas do Prazer: o lazer no pensamento biblioteconômico-informacional e sua dimensão aplicada na institucionalidade das bibliotecas

\title{
Percursos Metodológicos
}

\begin{abstract}
A grande mudança teve início em meados do século XVIII, como resultado dos novos impulsos estéticos, que assumiam tanto a forma clássica quanto a romântica, embora a corrente romântica seja a mais forte.
\end{abstract}

Huizinga (2010, p. 224)

Os procedimentos metodológicos orientaram-se para uma análise do espaço da biblioteca como um espaço de lazer, através do pensamento biblioteconômico-informacional. As seguintes fontes referenciais foram adotadas para a determinação e qualificação dos descritores adotados na etapa de recuperação bibliográfica e definição do corpus: "Dicionário de biblioteconomia e arquivologia" (2008); "Dicionário do Livro: Da Escrita ao Livro Eletrônico" (2008); Díccionario de bibliotecología; términos relativos a la bibliología, bibliofrafía, bibliofilía, biblioteconomia, archivología, documentología, tipografía y matérias afines (1976); e Dictionnaire encyclopédique de l'information et de la documentation (1997).

A partir das fontes mencionadas, os descritores selecionados foram: lazer, entretenimento, ação cultural (incluindo: ação), animação (incluindo: animar, animador e animado), animação cultural, animação de bibliotecas, biblioteca, bibliotecário e bibliotecárioanimador. Fontes gerais de informação, como dicionários da língua portuguesa, também foram adotadas para o estabelecimento de possíveis noções que poderiam colaborar com ampliação da visão sobre a terminologia especializada.

No Diccionario de bibliotecología; términos relativos a la bíbliología, bíbliofrafía, bibliofilia, biblioteconomia, archivología, documentología, tipografía y matérias afines (1976), foram reconhecidos os seguintes descritores: "ócio", "entretenimento", acción cultural", "animación cultural", "biblioteca de animación" e "biblioteca". No Dictionnaire encyclopédique de l'information et de la documentation (1997), os descritores pesquisados foram: loisirs, divertissement, action culturelle, animation, animation culturelle, animations bibliothèque e bibliothèque. Embora pesquisados, os dicionários em língua estrangeira não foram utilizados por não serem considerados relevantes para a construção global do estudo, já que a única palavra encontrada em ambos foi "biblioteca”, cuja definição não pareceu pertinente à especificidade do presente enfoque.

Quanto aos descritores adotados nos periódicos e nas bibliotecas digitais de teses e dissertações (BDTD's), estes foram os mesmos - lazer, entretenimento, ação cultural, animação e animação cultural. Quando necessário, foram cruzados com o termo biblioteca.

InCID: R. Ci. Inf. e Doc., Ribeirão Preto, v. 7, n. 1, p. 05-28, mar./ago. 2016. 
Foi realizado o levantamento bibliográfico em periódicos nacionais da área de Biblioteconomia, Ciência da Informação e Documentação, estes, avaliados pela CAPES entre as classificações A1, A2, A3 e B1. Esse recorte foi feito a fim de se consultar artigos de maior qualidade e que, simultaneamente, fosse possível obter um número significativo de periódicos para se pesquisar.

A pesquisa nos periódicos obteve como resultado 19 (dezenove) artigos significativos para o objeto investigado. Os periódicos que apresentaram resultados foram: Informação \& Sociedade (UFPB. Online); Biblionline (João Pessoa); Encontros Bibli; Pesquisa Brasileira em Ciência da Informação e Biblioteconomia; Perspectivas em Ciência da Informação (Online); Revista Digital de Biblioteconomia e Ciência da Informação; e InCID: Revista de Ciência da Informação e Documentação.

O recorte temporal da pesquisa cobriu todo o percurso retrospectivo das revistas até 2014. O levantamento foi complementado pelo estudo da Biblioteca Digital de Teses e Dissertações (BDTD) do Instituto Brasileiro de Informação em Ciência e Tecnologia (IBICT), etapa esta suplementada, ainda, pela revisão nas bibliotecas digitais de teses e dissertações locais. As BDTDs pesquisadas correspondem às unidades de ensino encontradas na lista da CAPES: "Relação de Cursos Recomendados e Reconhecidos" (grande área: ciências sociais aplicadas / área: ciência da informação).

A pesquisa nas BDTDs resultou em 8 (oito) dissertações significativas para este estudo. Os trabalhos duplicados não foram considerados na contagem. Observa-se que nos periódicos e nas BDTDs a quantidade de textos encontrados e considerados significativos para a pesquisa é baixa. Desta forma trata-se de assuntos pouco discutidos no campo. As BDTDs referentes a estes 8 (oito) trabalhos encontrados são bibliotecas das seguintes unidades de ensino: Instituto Brasileiro de Informação em Ciência e Tecnologia (IBICT); Universidade de São Paulo (USP); Universidade Estadual de Londrina (UEL); Universidade Federal de Santa Catarina (UFSC); Universidade Federal de Minas Gerais (UFMG).

Não foram encontradas teses significativas quanto aos descritores buscados, somente dissertações. Deve-se lembrar de que o tema do trabalho foi o que norteou a avaliação dos textos encontrados. Foi observado durante o levantamento nos periódicos e nas BDTDs que a maioria dos trabalhos encontrados trata dos domínios "biblioteca escolar" e "biblioteca pública". 
Das Políticas do Prazer: o lazer no pensamento biblioteconômico-informacional e sua dimensão aplicada na institucionalidade das bibliotecas

Mesmo não sendo o intuito do estudo a verticalização quantitativa, para identificação das autoridades no domínio investigado, buscou-se uma breve análise preliminar das referências mais mencionadas nas teses e dissertações. Isto resultou no critério de seleção de outras fontes para consulta e reflexão. O "Dicionário crítico de política cultural: cultura e imaginário", por exemplo, foi encontrado diversas vezes nas referências das dissertações, assim como os artigos, da década de 80, de Victor Flusser, e os livros de Luis Milanesi (1985, 1986, 2002). Os seguintes livros também pareceram relevantes diante do elevado nível de citações: "O que é ação cultural" de Teixeira Coelho; "O que é lazer" de Luiz Camargo. Estes são exemplos dos textos que foram consultados. Na leitura analítica dos artigos de periódicos, foram observados também outros documentos (livros ou artigos) que contemplassem a área e deveriam ser analisados, como o livro: "Biblioteca pública” de Almeida Júnior (2013).

Além das leituras selecionadas durante a condução metodológica da pesquisa, foram selecionados também os seguintes documentos que vão ao encontro do tema deste trabalho: "Caminhos transdisciplinares para a formação de bibliotecários" de Vieira (1983); "História da biblioteca como evolução de uma ideia e de um sistema" de Serrai (1975); "Introdução à biblioteconomia" de Fonseca (2007); "Biblioteca escolar" de Pimentel (2007); "Introdução à Constituição Federal e os Direitos Sociais Básicos ao Cidadão Brasileiro" de Pessoa (2011); e o Artigo $6^{\circ}$ da Constituição Federal de 1988, com redação dada pela emenda constitucional $n^{\circ} 64$, de 4 de fevereiro de 2010, o qual se refere aos direitos sociais do cidadão brasileiro.

Recorreu-se ainda aos manifestos e diretrizes da IFLA (The International Federation of Library Associations and Institutions), a saber: "Manifesto IFLA/UNESCO para biblioteca escolar" (200-?); "Diretrizes da IFLA/UNESCO para bibliotecas escolares" (2005); "Manifesto da IFLA/UNESCO sobre bibliotecas públicas" (2004); e "Diretrizes da IFLA sobre os serviços da biblioteca pública", $2^{\text {a }}$ edição (2013). 
Gustavo Silva Saldanha e Rachel de Melo Vellozo Pereira

\title{
A física do desejo, ou da biblioteca e seu espaço: introdução às abordagens sobre o lazer no pensamento biblioteconômico-informacional
}

\begin{abstract}
Um problema muito diferente é procurar determinar o conteúdo lúdico da ciência moderna, pois aí deparamos com uma dificuldade fundamental.
\end{abstract}

Huizinga (2010, p. 225)

Apresentamos aqui os resultados centrais da pesquisa, destacando a relação entre o espaço físico da biblioteca e os desdobramentos da análise bibliográfica no pensamento biblioteconômico-informacional. Acredita-se que a forma como o espaço da biblioteca é pensado e "materializado" possa interferir nas ações praticadas nestes ambientes. Em seguida foram descritas possíveis abordagens que levam o lazer a ser "conquistado" em bibliotecas.

\section{$3.1 \mathrm{O}$ espaço da biblioteca}

Como fonte central dos argumentos sobre a construção e a utilidade do espaço da biblioteca como território do lazer, identificou-se o amplo uso do pensamento de Milanesi (1985, 1986, 2002) em BCI. Na visão do autor, primeiramente, deve-se dizer que é essencial a relação entre o espaço e a função da biblioteca, e que espaço por si só, não produz a função, mas ajuda (MILANESI, 1986, p. 245-230).

O espaço da biblioteca é apenas um suporte, necessário e significativo, para que a biblioteca possa praticar suas funções. Este espaço pode sugerir invenções, ou as invenções podem sugerir novos espaços; embora existam limites, mas será dentro destes que haverá a criação de novos ambientes físicos (MILANESI, 1986, p. 250).

Para isto, "É importante que as necessidades específicas de qualquer comunidade sejam o principal fator a determinar o espaço atribuído à biblioteca" (IFLA, 2013, p. 101). Embora a IFLA (2013) esteja se referindo à biblioteca pública, esta afirmação é válida para as demais categorias de bibliotecas. Gonçalves (2011, p. 27-28) ressalta que "[...] o prédio da biblioteca tem que estar bem localizado, com instalações adequadas para leitura, estudo e atividades culturais, assim como precisa dispor de recursos tecnológicos e horário de funcionamento conveniente aos usuários".

Geralmente, a biblioteca assume um espaço já construído, ou seja, a biblioteca não ocupa um espaço o qual foi construído para ela. Alguns "arquitetam" um espaço que se resume em dois ambientes: depósitos de livros e o local de leitura. Raramente pensa-se num espaço para circulação de pessoas entre informações (como livros, revistas, vídeos, palestras, filmes, 
Das Políticas do Prazer: o lazer no pensamento biblioteconômico-informacional e sua dimensão aplicada na institucionalidade das bibliotecas

recitais, discos, jornais etc.). O pouco que se investe com a arquitetura é justificado, em geral, pela ideia de que fazer cultura não exige, necessariamente, grandes investimentos. Visto que se tem a ideia que a biblioteca se adapta a qualquer casa (MILANESI, 1985, p. 93-94), ou melhor, a qualquer local fechado. Neste sentido, “A própria pertinência da construção de uma biblioteca deverá ser discutida. É necessário averiguar se dentro dos limites orçamentários ela é prioritária. (MILANESI, 1986, p. 246). Ao contrário disto “A biblioteca pode nascer numa sala, num galpão" (MILANESI, 1986, p. 257).

Observa-se que a construção da biblioteca é uma representação de como esta organização é vista por quem a desenvolve. É um ponto de vista que pode interferir em todo o processo de crescimento e apropriação do espaço. Visto que as bibliotecas públicas e escolares podem vir a ter como objetivo o lazer, não pensar em espaços favoráveis para estas práticas é contraditório. Ou simplesmente não pensar em espaços para o diálogo e interação social dos usuários, torna qualquer tipo de biblioteca um lugar limitado quanto à circulação e interação social.

\begin{abstract}
No instante em que se discute o espaço adequado para as funções de informar e conviver, abre-se uma nova perspectiva para a biblioteca enquanto construção. A sala única torna-se sem sentido. Ou mesmo várias salas para estocar livros e leitores deixa de ser a meta, passando a ser uma parte. [...] Dentro da ideia de que é preferível pessoas conversando do que livros fechados ou mal lidos, é necessário que se reforce o espaço destinado à relação humana. (MILANESI, 1986, p. 248).
\end{abstract}

Sendo assim, quando os profissionais que desenvolvem a biblioteca interpretam o seu espaço como um espaço em geral silencioso, isto pode interferir no diálogo entre os usuários e nas atividades de entretenimento entre estes. $\mathrm{O}$ ideal seria que houvesse espaços restritos para a leitura, ou seja, local de silêncio, desta forma isto não limitaria a convivência das pessoas nos demais ambientes da biblioteca. Afinal, “[...] a biblioteca deve se tornar um espaço aberto, de diálogo e sobretudo de convivência, um verdadeiro ponto de convergência das manifestações culturais em todas as suas formas, onde qualquer pessoa possa se expressar" (CABRAL, 1989, p. 31, grifo nosso).

Ressalta-se que o diálogo, a interação e a convivência, entre usuários são assuntos significativos para este trabalho, visto que por meio destes, pode-se promover o entretenimento entre "grupos", não limitando o usuário à prática de um "lazer solitário".

Desta forma, o usuário pode se distrair, se divertir, ao fazer uma leitura ou assistir a um filme só, e também pode ter a opção de realizar estas práticas em grupos no espaço da biblioteca. Para isto é preciso que no mínimo a biblioteca não limite o diálogo entre seus usuários. Posto 
que a biblioteca “[...] deve ser um local de encontro e discussão [...]” (MILANESI, 1985, p. 93).

É importante frisar que cada biblioteca tem o seu contexto, seus objetivos e suas limitações. Há limitações quanto ao seu espaço, sua renda financeira, e estes fatores tornam mais complexo o desenvolvimento de diversos espaços/salas diferentes, uma para cada tipo de atividade. Em geral, o local de leitura já é entre os livros, já é ao lado do balcão de referência, e neste contexto é mais dificultoso falar sobre diálogo e interação entre usuários. Visto que é um ambiente, quase que totalmente silencioso, pois as primeiras, se assim podem ser chamadas, necessidades do público, em geral, são pesquisar, ler e estudar. Há ainda bibliotecas que não consideram dentre os seus objetivos o lazer, assim como há bibliotecas que consideram esta possibilidade de atividade em seu espaço.

Milanesi (1985, p. 100) defende que o espaço tradicional da biblioteca, onde o público teria fácil acesso às obras e condições para ler e escrever, é “[...] alimentado mais pelas exigências formais da escola pública e menos pela necessidade de lazer ou uma aproximação espontânea do conhecimento". Dito isto, percebe-se que as bibliotecas podem ter a tendência em serem mais voltadas para as "obrigações" do usuário, do que para suas ações de "liberdade" (linha de pensamento quanto ao lazer, ver o tópico 3.2).

Retornando ao assunto sobre a existência de vários espaços na biblioteca, um para cada tipo de atividade, defende-se que a ideia que se tem de espaço de lazer pode não ser necessariamente em um local fixo. O mesmo salão silencioso poder ser amanhã um local de entretenimento. Assim como um local de diálogos pode vir a ser um local de leitura e silencioso. A biblioteca é livre para realizar modificações, mesmo que temporárias, para desenvolver suas ideias, quanto ao seu espaço, seus serviços e produtos.

Pimentel (2007, p. 104) defende que "Se a biblioteca não for um local acolhedor e confortável, poucos aí se sentirão bem e provavelmente buscarão outras alternativas de lazer”. Apesar de o autor defender esta ideia no contexto da biblioteca escolar, esta é uma afirmativa válida também para os demais tipos de bibliotecas. “[...] a informação pública, reduzida a bibliotecas municipais, não é competitiva como instrumento de disseminação e, muito menos, como espaço de lazer. Assim, perde clientes, espaço e, em muitos casos, a razão de existir" (MILANESI, 2002, p. 95). Através desta citação percebe-se uma visão de biblioteca, não caracterizada como um espaço de lazer competitivo entre outros ambientes. Para a biblioteca vir a competir com outros espaços que proporcionam lazer, esta precisa visualizar o usuário InCID: R. Ci. Inf. e Doc., Ribeirão Preto, v. 7, n. 1, p. 05-28, mar./ago. 2016. 
Das Políticas do Prazer: o lazer no pensamento biblioteconômico-informacional e sua dimensão aplicada na institucionalidade das bibliotecas

como um cliente. Assumir que há outros ambientes para este praticar o seu "bem-estar" e sua "liberdade" (linha de pensamento quanto ao lazer, ver o tópico 3.2), e que estes podem ser mais atrativos ou tão atrativos quanto a biblioteca.

Para que o espaço biblioteca de fato "represente" seu público-alvo é defendida a ideia de que "O usuário necessita ter maior autonomia no espaço da biblioteca e no uso do seu sistema, a fim de poder exercer a sua individualidade e criatividade” (TSUPAL, 1987, p. 163). Afinal, "A biblioteca, como instituição social, influencia e é influenciada pelo ambiente" (GONÇALVES, 2011, p. 24).

Não basta a biblioteca elaborar seu espaço, seus produtos e serviços, somente, e aguardar o uso destes. O bibliotecário pode interpretar que, uma vez que tais elementos são necessidades de seus usuários, estes descobrirão a potencialidade de tais elementos utilizados e aproveitarão o potencial que estes têm para servi-los. Este pensamento pode influenciar no uso "negativo", pouco uso ou nenhum uso destes espaços, produtos e serviços. A animação cultural, por exemplo, pode vir a incentivar o uso dos produtos e serviços da biblioteca, sendo assim também pode promover o seu espaço para que este seja mais utilizado (linha de pensamento quanto ao lazer, ver o tópico 3.2). Mas apenas elaborar espaços, produtos e serviços em prol do lazer na biblioteca não é o suficiente, pois é preciso promovê-los e contextualizá-los.

Se uma biblioteca apresenta, por exemplo, uma coleção de filmes (para entretenimento), uma sala de vídeo, e um atendimento voltado para seu uso, mas não divulga, não contextualiza estes elementos com atividades/eventos - como um dia de "sessão cinema" na biblioteca, ou a disponibilização de filmes voltados para tal data comemorativa (dia dos pais, dia das mães, natal etc.) - estes podem vir a ser poucos utilizados, ou não utilizados ou ainda "mal" utilizados (no sentido do usuário não conhecer a potencialidade do espaço, produto e serviço oferecido). Desta forma “A biblioteca então não só deve dispor de informações, mas oferecer uma série de atividades que dê sentido a elas" (MILANESI, 1986, p. 226).

Frisa-se que a animação cultural pode, através de atividades e eventos, incentivar o uso dos serviços e produtos da biblioteca. Essas atividades e eventos podem ser um caminho para contextualizar e promover o espaço, os serviços e os produtos, pertinentes ao lazer na biblioteca ou qualquer outra temática. Já a ação cultural - a qual pretende, basicamente, desenvolver a disponibilização, mediação e acesso da informação; uso de informação; criação e produção informacionais; diálogo, interação e participação do público - pode utilizar de seus processos 
como meio para também vir a contextualizar e promover o espaço, os serviços e os produtos (da biblioteca) referentes ao lazer.

A implantação de auditórios na biblioteca pode vir a ser um local específico e fixo para a elaboração de eventos a fim de promover o lazer, visto que

O auditório possibilita a realização de conferências, cursos, recitais, encenações, apresentação de filmes ou qualquer outro evento decidido pela coletividade. Também devem ser previstos espaços para exposições e, isso é fundamental, locais de convivência, onde ocorrerá a ação mais importante que uma biblioteca propiciará: a troca de informações entre as pessoas. (MILANESI, 1985, p. 103).

Lembrando que esta "troca de informações entre pessoas" é essencial para que haja novos diálogos e novas interações, possibilitando o entretenimento entre grupos.

Segundo a IFLA (2013), dentre as características que o espaço da biblioteca deve proporcionar, no contexto da biblioteca pública, destacam-se as seguintes características:

$[\ldots]$

- $\quad$ espaços de reunião para grupos de várias dimensões

[...]

- nas secções infantis podem ser disponibilizados brinquedos e equipamento de diversão

- $\quad$ as seções destinadas aos jovens podem incluir equipamento para jogos de computador, zonas de descontração com mobiliário confortável e televisores [...] (IFLA, 2013, p. 52).

Dito isto, percebe-se uma biblioteca a fim de promover o diálogo entre grupos, assim como a disponibilização de materiais para diversão, zonas de descontração e conforto. Afinal,

[...] a biblioteca não pode ser vista como um depósito de livros, mas como um ambiente onde o usuário permaneça à vontade. [...] A adequação entre público/informação/espaço permitirá tornar a biblioteca útil e agradável. [...] O espaço adequado é um reforço ao aproveitamento integral dos serviços oferecidos e mesmo um atrativo para o público. (MILANESI, 1986, p. 194). 
Das Políticas do Prazer: o lazer no pensamento biblioteconômico-informacional e sua dimensão aplicada na institucionalidade das bibliotecas

\section{Abordagens sobre o lazer no espaço físico das bibliotecas}

Apresentam-se duas abordagens que tratam sobre a "conquista" do lazer no espaço físico interno das bibliotecas. São elas: abordagem sobre ação cultural e animação cultural, proporcionando espaço de lazer na biblioteca; e a abordagem sobre a biblioteca como espaço de lazer.

As abordagens obtiveram como retorno para construção de um referencial teórico os seguintes autores:

- Referente à ideia de espaço de lazer na biblioteca: Milanesi (1985, 1986, 2002);

- Referente à ideia de lazer: Camargo (1986) e Coelho (1997);

- Referente à ideia de ação cultural e animação cultural: Coelho (1997), Gonçalves (2011), Flusser (1983), Cabral (1989), Silva (1991), Milanesi (2002), Sanches e Rio (2010), Andretti, Calegaro e Machado (2008), Cunha e Cavalcanti (2008).

Nas duas abordagens não se definiu se, dentro de seus objetivos, o lazer é diretamente um deles, e também não há categorização quanto ao tipo de biblioteca, como por exemplo: biblioteca escolar, pública, universitária etc., visto que para ambos os casos seria necessária uma pesquisa mais direcionada e específica. Desta forma há uma generalização, pois estes enfoques não abrangeram todo o conteúdo visto até então, neste trabalho, e também não esgotam todas as possibilidades de lazer em bibliotecas. São abordagens entendidas como "o despertar" para o desenvolver de outras abordagens mais concretas, com referencial teórico mais diversificado, análises mais profundas e com pesquisa de campo.

O primeiro enfoque, abordagem sobre ação cultural e animação cultural proporcionando espaço de lazer na biblioteca, apresenta o lazer sendo "conquistado" através da ação cultural e animação cultural. Mas antes de apresentar as abordagens, é preciso determinar quais as vertentes que foram utilizadas quanto aos conceitos: ação cultural, animação cultural e lazer.

Quanto à ação cultural consideram-se as seguintes vertentes:

- Uso: os autores Coelho (1997) e Gonçalves (2011) citam a ação cultural como meio para desfrutar ou consumir informações. Essas “informações" são chamadas por Coelho (1997) de "obras" e por Gonçalves (2011) de "cultura"; 
- Criação e produção: os autores Flusser (1983), Cabral (1989), Silva (1991), Coelho (1997) e Gonçalves (2011) caracterizam a ação cultural como um caminho para que o indivíduo, para quem é designada a ação cultural, possa criar e produzir obras, para este não ser apenas um utilizador de acervos mas também produtor. No caso do autor Milanesi (2002) este refere-se à criatividade, não necessariamente como uma criação ou produção. Já os autores Sanches e Rio (2010) defendem a ideia de criação no sentido de se repensar o novo a partir do antigo, possibilitando assim um processo contínuo de libertação intelectual;

- Diálogo, interação e participação: somados os conceitos de ação cultural de Cabral (1989), Andretti, Calegaro e Machado (2008), e Gonçalves (2011) observa-se que o diálogo, a interação e a participação do público, são funções da ação cultural.

Duas vertentes não foram consideradas. São elas: "disponibilização, mediação e acesso" - pois entende-se que esta já está inclusa na vertente "uso" -; e "atividades e eventos". Como mencionado, as atividades e eventos são promovidos pela animação cultural, podendo esta vertente ser "conquistada" na ação cultural, através da animação cultural. Esta ideia tem como base os autores Silva (1991) e Coelho (1997). Visto que a ação cultural “[...] na maioria das vezes inclui uma animação cultural, até como veículo de divulgação" (SILVA, 1991, p. 61); e que ação cultural de serviços, ou seja, uma forma de animação cultural é ato de promover a utilização de produtos, como um livro, um espetáculo etc. (COELHO, 1997).

Quanto à animação cultural, considera-se a seguinte vertente:

- Incentivo ao uso de serviços e produtos: são desenvolvidos atividades e eventos para estimular o uso de serviços e produtos, no contexto da biblioteca. Esta observação é uma soma das conceituações de animação cultural a partir dos autores Silva (1991), Cunha e Cavalcanti (2008), Sanches e Rio (2010). A animação cultural ainda pode ser vista como um "atrativo" para divulgar seus serviços e produtos, podendo funcionar como um “marketing" da biblioteca, segundo Silva (1991).

Por fim, apresentam-se as vertentes quanto ao lazer, as quais foram utilizadas em sua totalidade nas duas abordagens elaboradas:

- Bem-estar: Camargo (1986) e Coelho (1997) remetem à ideia de lazer associada à busca de prazer, realização pessoal e à autossatisfação; 
Das Políticas do Prazer: o lazer no pensamento biblioteconômico-informacional e sua dimensão aplicada na institucionalidade das bibliotecas

- Liberdade: Camargo (1986) e Coelho (1997) caracterizam lazer como um ato liberatório de obrigações, sendo o lazer um tempo concedido ao indivíduo após este ter cumprido suas obrigações.

Frisa-se também que se considera entretenimento o "Ato de entreter. Distração, passatempo, divertimento" (MICHAELIS, 1998, p. 824), com base neste conceito, o presente trabalho utilizou a palavra "diversão" como sinônimo de entretenimento.

Após a retomada sobre as vertentes e a explicação quanto a suas escolhas, lembra-se que se considera, neste trabalho, que para o entretenimento ocorrer, o "bem-estar" e a "liberdade" foram conquistados pelo indivíduo. Desta forma, quando se cita entretenimento, entende-se que as ideias de "bem-estar" e "liberdade" também estão inclusas. Assim, a palavra entretenimento foi utilizada no sentido de "auge" do lazer.

Com base no que foi dito até o momento, segue a Figura 1, a qual representa a abordagem sobre ação cultural e animação cultural proporcionando espaço de lazer na biblioteca.

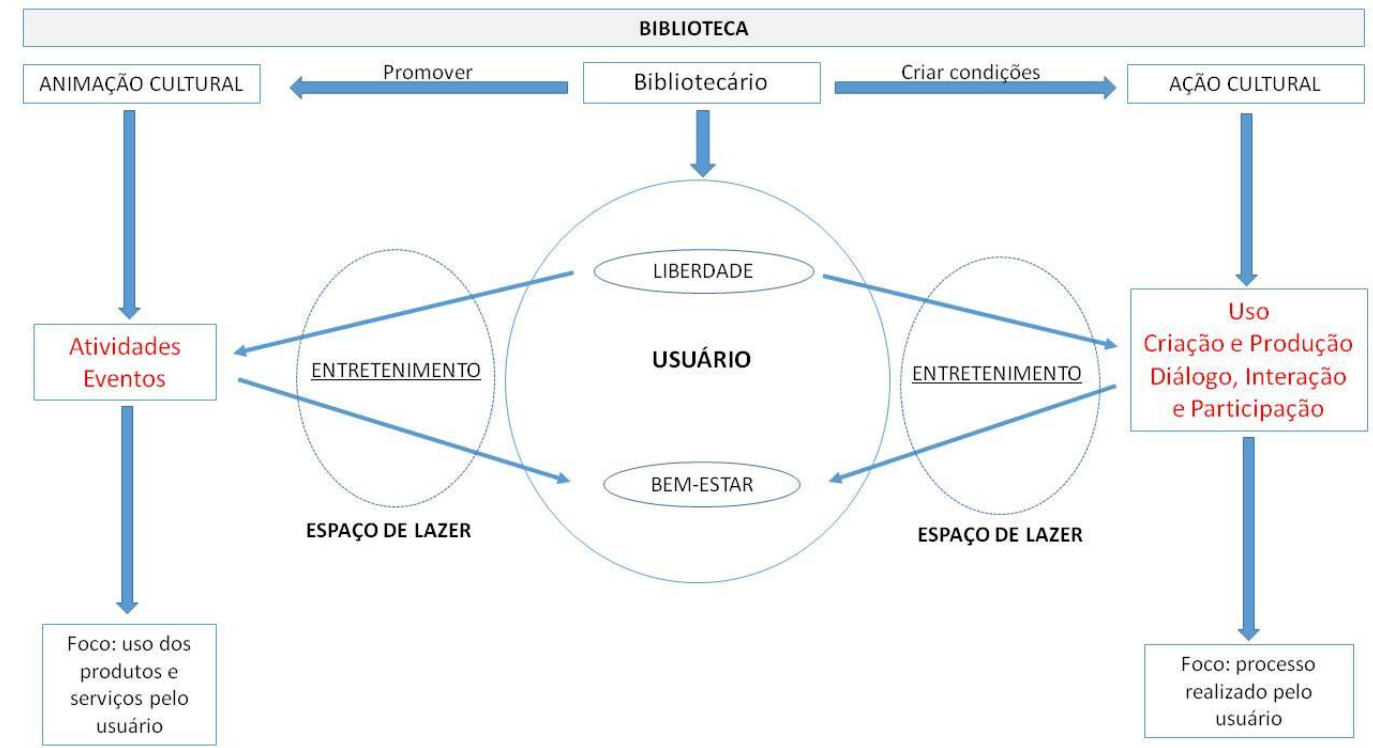

Figura - 1 Abordagem sobre ação cultural e animação cultural proporcionando espaço de lazer na biblioteca. Fonte: Rachel Pereira (2014), a partir de Milanesi (1985, 1986, 2002), Camargo (1986), Coelho (1997), Gonçalves (2011), Flusser (1983), Cabral (1989), Silva (1991), Sanches e Rio (2010), Andretti, Calegaro e Machado (2008), Cunha e Cavalcanti (2008).

A Figura 1 representa a animação cultural sendo promovida pelo bibliotecário, o qual desenvolve as atividades e eventos, tendo como foco o uso dos produtos e serviços da biblioteca. Se o usuário presente nestas atividades e eventos está "fazendo uso" de sua "liberdade", e essas tais atividades e eventos despertarem neste usuário o "bem-estar", pode-se InCID: R. Ci. Inf. e Doc., Ribeirão Preto, v. 7, n. 1, p. 05-28, mar./ago. 2016. 
dizer que há possibilidades de entretenimento por parte do usuário, ou seja, o desfrutar do lazer, a diversão. O espaço de lazer é "conquistado", mesmo que seu "auge” não seja alcançado - o mesmo vale para a ação cultural, e para a próxima abordagem, voltada para a biblioteca como espaço de lazer.

Frisa-se que a nomeação de "agentes culturais" (COELHO, 1989, 1997) faz referência ao sujeito que trabalha com a ação cultural. Desta forma a Figura 1 representa a ação cultural, tendo como agente cultural, o bibliotecário, o qual tem que “[...] reconhecer que na ação cultural seu objetivo não é criar diretamente, mas apenas criar as condições para que os outros o façam" (COLEHO, 1989, p. 65).

Desta forma, como mostra a Figura 1, o bibliotecário pode criar condições para que o usuário desfrute das potenciais ações culturais, entendidas como um processo, neste caso: o uso de informações; a criação e produção informacionais; o diálogo, interação e participação do usuário na ação cultural. Se o usuário estiver utilizando de sua liberdade para realizar tal processo, e se este processo lhe causar bem-estar, este conjunto de fatores (acredita-se) favorece o gozo do entretenimento por sua parte. Percebe-se assim a atualização de um espaço de lazer potencial, assim como em animação cultural.

Observa-se ainda na Figura 1 que o bibliotecário está relacionado com o usuário, através de um vetor, o qual tem como objetivo lembrar que o principal foco, tanto na abordagem sobre ação cultural e animação cultural proporcionando espaço de lazer (Figura 1), como na abordagem sobre a biblioteca como espaço de lazer (Figura 2), é o usuário. Como já dito anteriormente, é preciso que o bibliotecário conheça suas necessidades e desejos para melhor atendê-lo, ou seja, tornar a biblioteca um espaço voltado para os interesses deste.

A Figura 2 que representa a abordagem sobre a biblioteca como espaço de lazer: 
Das Políticas do Prazer: o lazer no pensamento biblioteconômico-informacional e sua dimensão aplicada na institucionalidade das bibliotecas

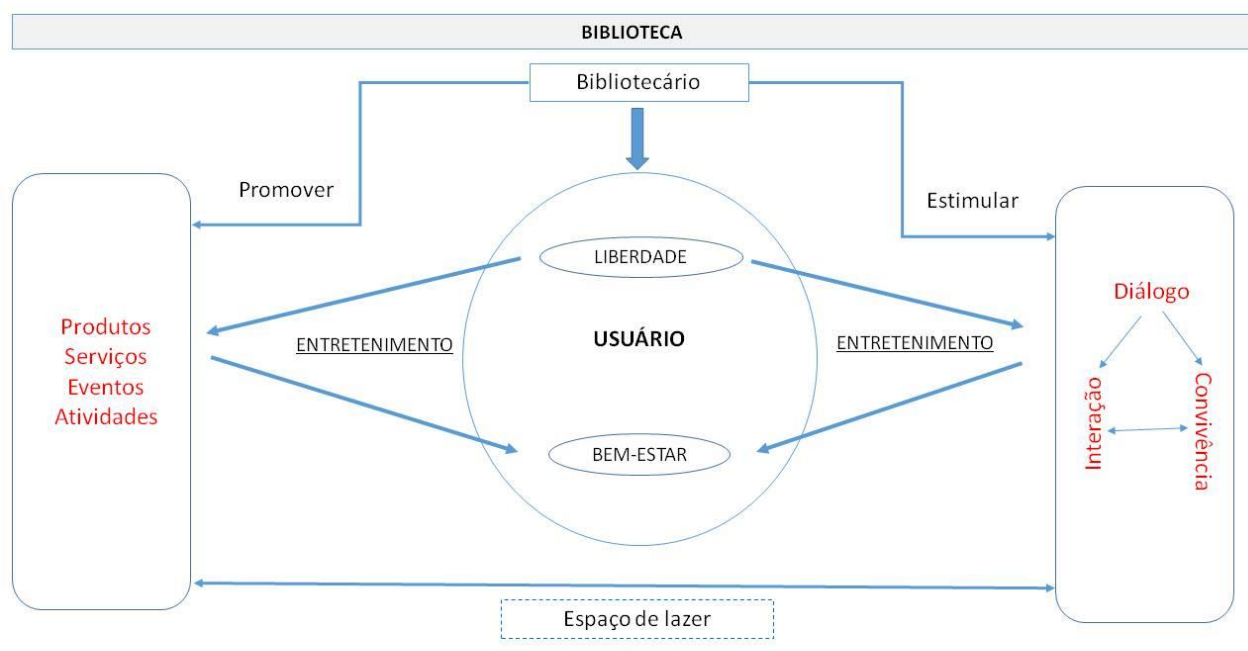

Figura - 2 Abordagem sobre a biblioteca como espaço de lazer.

Fonte: Rachel Pereira (2014), a partir de Milanesi (1985, 1986, 2002) e Michaelis (1998).

A Figura 2 representa uma biblioteca como um espaço de lazer, sem recorrer às ideologias de ação cultural e animação cultural. Observa-se o bibliotecário promovendo os produtos, serviços, eventos e atividades; e estimulando o "triângulo do diálogo".

Partindo dos conceitos:

- Diálogo: “Conversação entre duas pessoas ou mais pessoas” (MICHAELIS, 1998, p. 716);

- Interação (social): “ações e relações entre membros de um grupo ou entre grupos de uma sociedade" (MICHAELIS, 1998, p. 1166);

- Convivência: “Ação ou efeito de conviver. Familiaridade, intimidade. Reunião de pessoas que convivem na mais estreita harmonia” (MICHAELIS, 1998, p. 580).

Acredita-se que o "triângulo do diálogo" representa o diálogo podendo desenvolver a interação e a convivência entre usuários; e a interação e a convivência podendo uma influenciar (positivamente ou negativamente) a outra.

Desta forma, conforme a Figura 2, se o usuário estiver utilizando de sua liberdade para utilizar dos serviços e produtos da biblioteca, assim como sua presença nas atividades e eventos desta, e se isto estiver lhe causando "bem-estar", acredita-se que o entretenimento, a diversão, pode ocorrer (situação 1). 
Acrescenta-se que se o usuário estiver usando de sua liberdade para participar do "triângulo do diálogo" e isto lhe causar bem-estar, pode-se dizer que neste caso também há chances para que o entretenimento venha a ser "conquistado" (situação 2). Defende-se ainda que a situação 1 pode ocorrer junto à situação 2 , e que estas duas situações podem influenciar (positivamente e negativamente) uma à outra.

Nos dois enfoques (abordagem sobre ação cultural e animação cultural proporcionando espaço de lazer na biblioteca; e a abordagem sobre a biblioteca como espaço de lazer) há possibilidades para a construção de espaços de lazer, para isto basta o usuário utilizar de sua "liberdade" em apenas um dos elementos (atividades, eventos, uso de itens informacionais, criação e produção informacionais, diálogo, interação e participação - Figura 1; produtos, serviços, eventos, atividades, diálogo, interação e convivência - Figura 2), e algum desses lhe causar bem-estar, para o espaço de lazer vir a ocorrer, podendo ocorrer ou o "estado" de diversão.

Em relação às duas abordagens, é válido informar que a atuação do bibliotecário está diretamente vinculada à sua formação acadêmica e suas experiências profissionais. Logo, é inviável demonstrar todo este processo em simples figuras. Deixa-se claro que a atuação do profissional nestas abordagens não abrange todas as suas atividades elaboradas na biblioteca, mesmo outras que poderiam ser contextualizadas com o espaço de lazer. Por outro lado, frisase o reconhecimento do alto grau de subjetividade sobre a qual se instala qualquer teorização sobre o lazer, tendo em vista a ampla margem de particularidade, para cada indivíduo, sobre o que é ou não o seu modo de divertir-se. Como afirma Coelho (1997, p. 227) firma-se ainda que “O lazer não se marca por um tipo definido ou privilegiado de atividade [...]”.

Desta forma, reconhecendo a biblioteca como espaço de lazer, noção esta inegavelmente subjetiva, considera-se que tal noção pode ser pensada a partir de uma política de intersubjetividades. Esta política responde por um processo permanente de compreensão dos modos de transformação das ações do leitor/usuário/visitante e todo o seu contexto sóciotécnico-cultural, ou seja, o conjunto de mutações que envolvem os gestos de prazer, de escolhas de entretenimento e de tendências de gostos. 
Das Políticas do Prazer: o lazer no pensamento biblioteconômico-informacional e sua dimensão aplicada na institucionalidade das bibliotecas

\title{
Considerações finais
}

\begin{abstract}
Portanto, a afirmação de que a ciência não passa de um jogo é uma afirmação gratuita, demasiado fácil, que se impõe provisoriamente. Mas é legítimo perguntar se não há na ciência um elemento lúdico, dentro do terreno circunscrito pelo seu método, como por exemplo na tendência de sistematizar que todo cientista possui, tendência de caráter parcialmente lúdico.

Huizinga (2010, p. 226)
\end{abstract}

Cabe-nos destacar alguns elementos centrais dos resultados, atentando para os questionamentos centrais. Tendo em vista a procura pela construção do discurso do lazer no pensamento biblioteconômico-informacional e seus modos de inserção no contexto institucional da biblioteca, as inferências abaixo tornaram-se fundamentais para os apontamentos conclusivos.

- Plano quantitativo da literatura especializada: percebeu-se um número baixo de estudos sobre a temática, e a centralidade em tipologias tradicionais, como "biblioteca escolar" e "biblioteca pública", sem uma abordagem crítica sobre a transversalização destas noções com abordagens contemporâneas;

- Idade da literatura especializada: notou-se também o enfoque em uma literatura não atual, sendo a noção de atualidade aqui considerada a partir das transformações dos anos 1990 e do século em curso (últimos 25 anos), principalmente no que diz respeito às mutações sócio-técnico-informacionais do período;

- Perspectivas políticas: a subjetividade das "políticas de prazer" não respondem por um abandono na possibilidade de estabelecimento de políticas de lazer no âmbito da institucionalidade das chamadas "sedes informacionais por natureza", como bibliotecas. As margens de intersubjetividade abertas pelos gestos coletivos da ação dos indivíduos são fonte objetiva para determinação de indicadores sazonais de "políticas de prazer", que se tornam objetivas na medida em que respondem por fundamentos estruturais do pensamento biblioteconômico-informacional, como o "Manifesto da IFLA /UNESCO sobre Bibliotecas Públicas” (2004), assim como da própria Constituição brasileira.

Um elemento central, que não nos coube aqui aprofundar, mas sugerir futuras investigações, está na relação entre "política" (no sentido teórico) e as ações biblioteconômicoinformacionais. Como aponta Cabral (1989, p. 157-158), “[...] a ação cultural bibliotecária é uma opção política, e envolve questionamentos como: 'a quem vamos servir?', trabalhar 'a favor de quem?', 'fazer o quê?', ‘por quê?’ e ‘como’?’ Segundo Coelho (1997, p. 292) “[...] a política cultural é entendida habitualmente como programa de intervenções realizadas pelo InCID: R. Ci. Inf. e Doc., Ribeirão Preto, v. 7, n. 1, p. 05-28, mar./ago. 2016. 
Estado, instituições civis, entidades privadas ou grupos comunitários com o objetivo de satisfazer as necessidades culturais da população e promover o desenvolvimento de suas representações simbólicas”.

Não há dúvida, para nossa reflexão, que o domínio aqui investigado coloca em xeque esta relação, a dialética arriscada entre política informacional e política cultural, como antevisto. O lazer é, antes, uma prática de "liberdade", logo, em geral, o cidadão não vai pedir permissão para tal, se este o quiser fazer. Mas ressalta-se que assim como há políticas que determinam limites quanto, por exemplo, ao uso do acervo, cabe à biblioteca pensar criticamente as possibilidades da construção do entretenimento. Isto demarca ainda mais o papel político do lazer no pensamento biblioteconômico-informacional, subentendido na discussão sobre o direito social.

O lazer visto como direito social é central para tal debate, porém não foi um enfoque constante da reflexão, dada a ausência de literatura biblioteconômico-informacional de sua ênfase. Para um estudo crítico reelaborado sob esta perspectiva, seriam necessárias, acreditase, investigações estruturadas em abordagens metodológicas de campo presenciais, visando compreender localmente as práticas de lazer em bibliotecas e suas políticas. As primeiras a serem estudadas, no ponto de vista desta reflexão, seriam as bibliotecas públicas e escolares, visto que estas guardam um enorme potencial de transformação crítica do sujeito. Atualizadas pesquisas bibliográficas poderiam ser comparadas a estas coletas, aprofundando a relação entre abordagens epistemológicas e intervenções no cotidiano.

Foram analisados possíveis enfoques (abordagem sobre ação cultural e animação cultural proporcionando espaço de lazer na biblioteca; e a abordagem sobre a biblioteca como espaço de lazer), os quais não abrangem todas as possíveis possibilidades de lazer em bibliotecas. Estes enfoques são um “despertar”, um incentivo, para a construção de novas abordagens mais consistentes, de preferência com o feedback dos usuários, pois a ideia de que nas bibliotecas ocorre o chamado espaço de lazer é subjetiva, uma suposição. Com o feedback pode-se vir a saber se o espaço de lazer em algum momento existiu/existe em uma determinada biblioteca.

Enfatiza-se que a biblioteca pode vir a ser um "concorrente" significativo dentre as diversas formas de lazer, para tal é preciso investimento, principalmente quanto ao atendimento aos usuários, ou seja, conseguir identificar seus principais anseios referentes ao lazer, como também antecipar as demandas de transformação, lançando mão de todo manancial plural de 
Das Políticas do Prazer: o lazer no pensamento biblioteconômico-informacional e sua dimensão aplicada na institucionalidade das bibliotecas

dados de um determinado acervo bibliográfico e pessoal (neste caso, indivíduos da comunidade e suas linguagens).

Retomando a questão norteadora do presente trabalho: no ponto de vista teórico biblioteconômico-informacional a biblioteca poderia proporcionar um espaço de lazer aos seus usuários? Neste estudo acredita-se que referente às bibliotecas públicas e escolares há uma tendência em proporcionar o lazer, embora sejam necessários estudos mais abrangentes e com pesquisa de campo. O mesmo deverá ser realizado para as outras categorias de bibliotecas, como as universitárias, nacionais, especializadas, infantis etc.

As respostas às indagações iniciais ainda ficam, em linhas gerais, em aberto. A relação entre as "políticas do prazer" e a liberdade intelectual e a liberdade de expressão, primariamente antevistas como correlacionadas, ainda carece de um aprofundamento metodológico na literatura biblioteconômico-informacional para o estabelecimento de suas fronteiras. Apartar uma "sociedade do espetáculo" de uma "sociedade da informação" ainda parece ser um procedimento arriscado, dada a complexidade de sobreposição de linguagens permitida pelas novas mídias. Não há dúvida, porém, que as instituições informacionais cumprem papel decisivo na crítica a ambas as ditas "sociedades". E a "liberdade de prazer" pode, sim, ser vislumbrada como "liberdade crítica das sensibilidades", permanentemente alertada sobre o imperialismo informacional vigente. O "deleite", suspeita-se, pode, sim, estar aquém e além do prazer cego, contrário às dinâmicas de dominação e alienação. No entanto, de fato, conclui-se aqui que a literatura biblioteconômico-informacional ainda carece de uma abordagem mais robusta e intervencionista neste sentido. 


\section{Referências}

ALMEIDA JÚNIOR, O. F. Biblioteca pública: avaliação de serviços. Londrina: Eduel, 2003.

ANDRETTI, C. R.; CALEGARO, É. M.; MACHADO, M. Da lagarta para borboleta: ação cultural como estratégia de marketing no sistema integrado de bibliotecas da UNIVALI SIBIUN. Revista ACB: Biblioteconomia em Santa Catarina, Florianópolis, v.13, n.1, p.189-200, jan./jun., 2008. Disponível em: <http://revista.acbsc.org.br/racb/article/view/542/668 >. Acesso em: 29 abr. 2014.

BYRNE, A. Promoting intellectual freedom globally through libraries: the Role of IFLA. Libri, v. 50, p. 57-65, 2000.

CABRAL, A. M. R. Ação cultural bibliotecária: aspectos revelados pela prática. Belo Horizonte: UFMG, 1989. Disponível em:

<http://www.bibliotecadigital.ufmg.br/dspace/handle/1843/BUOS-933EC5>. Acesso em: 29 abr. 2014.

CAMARGO, L. O. L. O que é lazer. São Paulo: Brasiliense, 1986.

COELHO, T. Dicionário crítico de política cultural: cultura e imaginário. São Paulo: Iluminuras, 1997. Disponível em:

$<$ http://portalpbh.pbh.gov.br/pbh/ecp/files.do?evento=download\&urlArqPlc=3confcult-

DicionarioCriticodePoliticaCultural.pdf. Acesso em: 29 abr. 2014.

O que é ação cultural. São Paulo: Brasiliense, 1989.

CUNHA, M. B.; CAVALCANTI, C. R. O. Dicionário de biblioteconomia e arquivologia. Brasília: Briquet de Lemos, 2008.

FLUSSER, V. A biblioteca como instrumento de ação cultural. Revista da Escola de Biblioteconomia da UFMG, Belo Horizonte, v. 12, n.2, p. 145-169, 1983. Disponível em: $<$ http://www.brapci.ufpr.br/documento.php?dd0=0000001973\&dd1=3c2a1 >. Acesso em: 29 abr. 2014.

GONÇALVES, M. G. S. A Biblioteca Pública do Paraná como instrumento de ação cultural: atividades e mediação da informação. Londrina, 2011. 120 p. Dissertação (Mestrado em Profissional em Gestão da Informação). Universidade Estadual de Londrina, Londrina, 2011. Disponível em:

$\langle$ http://www.bibliotecadigital.uel.br/document/?code=vtls000173811 >. Acesso em: 29 abr. 2014.

GONZÁLEZ DE GÓMEZ, M. N. Novos cenários políticos para a informação. Ciência da Informação, Brasília, v. 31, n. 1, p. 27-40, jan./abr. 2002.

HUIZINHA, J. Homo ludens: o jogo como elemento da cultura. 6. ed. São Paulo: Perspectiva: 2010.

IFLA. Manifesto da IFLA/UNESCO sobre bibliotecas públicas. 2004. Disponível em: <http://archive.ifla.org/VII/s8/unesco/port.htm>. Acesso em: 29 abr. 2014. 
Das Políticas do Prazer: o lazer no pensamento biblioteconômico-informacional e sua dimensão aplicada na institucionalidade das bibliotecas

IFLA. Manifesto da IFLA/UNESCO sobre biblioteca escolar. 2005. Disponível em: $<$ http://www.ifla.org/files/assets/school-libraries-resource-centers/publications/school-libraryguidelines/school-library-guidelines-pt_br.pdf> . Acesso em: 29 abr. 2014.

Diretrizes da IFLA sobre os serviços da biblioteca pública. 2. ed. Lisboa: De Gruyter saur, 2013. Disponível em: <http://www.ifla.org/files/assets/hq/publications/series/147-pt.pdf>. Acesso em: 29 abr. 2014.

MICHAELIS: moderno dicionário da língua portuguesa. São Paulo: Companhia Melhoramentos, 1998.

MILANESI, L. Biblioteca. Cotia: Ateliê Editorial, 2002.

O que é biblioteca. 3. ed. São Paulo: Brasiliense, 1985.

Ordenar para desordenar: centros de cultura e bibliotecas públicas. 2. ed. São Paulo: Brasiliense, 1986.

PEREIRA, R. M. V. A biblioteca como espaço de lazer: análise dos estudos sobre entretenimento no pensamento biblioteconômico-informacional. Rio de Janeiro, 2014. 78 p. Monografia (Bacharelado em Biblioteconomia) - Universidade Federal do Estado do Rio de Janeiro, Rio de Janeiro, 2014.

PIMENTEL, G. Biblioteca escolar. Brasília: Universidade de Brasília, 2007. Disponível em: <http://portal.mec.gov.br/seb/arquivos/pdf/profunc/biblio_esc.pdf>. Acesso em: 29 abr. 2014.

SANCHES, G. A. R.; RIO, S. F. Mediação da informação no fazer bibliotecário e seu processo em bibliotecas universitárias no âmbito das ações culturais. InCID: Revista de Ciência da Informação e Documentação, Ribeirão Preto, v. 1, n. 2, p. 103-121, jul./dez. 2010. Disponível em: 〈http://www.revistas.usp.br/incid/article/view/42323/45994>. Acesso em: 29 abr. 2014.

SERRAI, A. História da biblioteca como evolução de uma idéia e de um sistema. Revista da Escola de Biblioteconomia da UFMG, v. 4, n. 2, p. 141-161, set., 1975.

SILVA, T. E. Ação cultural e biblioteca pública: algumas questões. In: CONGRESSO BRASILEIRO DE BIBLIOTECONOMIA E DOCUMENTAÇÃO, 16, 1991, Salvador. Anais... Salvador: Associação Profissional dos Bibliotecários do Estado da Bahia, 1991. Disponível em: 〈http://eprints.rclis.org/14827/1/AcaoCultural_e_BibliotecaPub.pdf>. Acesso em: 29 abr. 2014.

TSUPAL, R. Leitura e atividades culturais na biblioteca pública: aspectos teóricos. Revista de Biblioteconomia de Brasília, Brasília, v. 15, n. 2, p. 149-165, 1987. Disponível em: $<$ http://www.brapci.ufpr.br/documento.php?dd0=0000002543\&dd1=bc8ab $>$. Acesso em: 29 abr. 2014. 